\title{
Diagnostic and prognostic role of renal histopathology in rheumatic diseases
}

\author{
F. Saccon, M. Gatto, M. Larosa, F. Ometto, M. Felicetti, R. Padoan, M. Zen \\ Division of Rheumatology, Department of Medicine, University of Padova, Padova, Italy
}

\begin{abstract}
SUMMARY
The objective was to evaluate renal involvement in several rheumatic diseases (i.e. rheumatoid arthritis, systemic lupus erythematosus, Sjögren syndrome, systemic sclerosis, systemic vasculitides).

The method chosen was to define histopathological profiles reported in renal biopsies performed on patients with renal involvement due to different rheumatic diseases.

Renal involvement observed in patients with rheumatic disease can be the direct result of the disease per se and/or a complication of drugs used in the disease treatment. The clinical-pathological correlations derived from the study of renal tissues can be useful for differential diagnosis, prognosis assessment and therapeutic decisions.

Renal biopsy should be considered as an important tool for the management of nephropathies in patients with systemic rheumatic diseases.
\end{abstract}

Key words: Renal involvement; Renal histopathology; Renal biopsy; Lupus glomerulonephritis; Autoimmune Rheumatic diseases.

Reumatismo, 2018; 70 (3): 165-177

\section{INTRODUCTION}

enal insufficiency, regardless of the etiology, is a well-known predictor of mortality. Several rheumatic diseases are associated with unequivocal and often severe renal involvement. However, especially for mild renal damage, it is not clear whether it results from the disease itself or whether it arises from the drug treatment of the disease, or both (1). In addition, renal co-morbidity (i.e. hypertension, diabetes mellitus, malignancy) is common in patients with rheumatic diseases (2).

\section{RHEUMATOID ARTHRITIS}

Urinary abnormalities and impaired renal function are reported in up to $30 \%$ of patients with rheumatoid arthritis (RA) (3, 4). In renal biopsies from RA patients, the most common histological findings are mesangial glomerulonephritis (GN), membranous nephropathy and secondary amyloidosis. These lesions have been related to chronic inflammation and drug toxicity, but no specific renal disease is considered a specific manifestation of RA.

Mesangial GN is found in 20-40\% of renal biopsies from RA patients and it is characterized by proliferation of mesangial cells (5-11). Immunofluorescence (IF) shows mesangial deposits of immunoglobulins and complement: IgM (33-78\%), IgA (8$57 \%)$ and C3 (8-40\%) (10-12). According to some Japanese studies, IgA-positive mesangial GN has peculiar associations, such as young age and severe haematuria; however, these observations were attributed to a population bias $(8,10)$. Mesangial GN is the most common histological pattern in biopsies from patients with haematuria but with normal renal function (10-13).

Membranous nephropathy is reported in one third of renal biopsies $(5-11,14,15)$. Histology shows diffuse subepithelial deposits of $\mathrm{IgG}$, with marked podocytic lesions and mesangial expansion $(10,11)$. The prevalence of membranous nephropathy increased between 1980 and 2010 due
Corresponding author: Francesca Saccon Division of Rheumatology, Department of Medicine, University of Padova

Via Giustiniani, 2 35128 Padova, Italy E-mail: saccon.francesca@libero.it 
to the large use of disease-modifying antirheumatic drugs (DMARDS) $(8,14)$. The association with DMARDS is confirmed in more than half of the cases, particularly with gold salts, penicillamine and bucillamine $(6-11,15,16)$. Membranous nephropathy is mostly observed in patients with normal renal function undergoing biopsy because of proteinuria $(10,11)$.

Frequency of renal amyloidosis decreased after the introduction of new effective treatments in RA (16-18). In recent studies, its frequency is $19-37 \%$ but amyloid deposits are found in almost all renal biopsies from RA patients with long disease duration (5, $7,8,11,12,14,15)$. Decrease in mesangial cells and atrophy of vessels, tubules and interstitium are often associated with amyloid deposits in the glomerulus (10, 16). Thus, amyloidosis is the main cause of reduced renal function and of renal failure in RA patients $(4,8,10,11,19)$.

Extracapillary GN is reported in $0-15 \%$ of RA renal biopsies $(10,11,14,20-23)$. Histology shows an extracapillary proliferation, necrotizing GN and, occasionally, crescents $(11,20,21)$. The clinical manifestation is severe, with rapidly progressing renal impairment and it is often associated with systemic vasculitic manifestations, positive RF (in 60-90\% of patients) and anti-neutrophil cytoplasmic antibody (ANCA) antibodies (in 20\%) $(11,20,21)$. A number of cases were related to treatment, specifically gold salts, penicillamine and tumor necrosis factor-alfa (TNF- $\alpha$ ) inhibitors (24-28).

A minor percentage of renal biopsies from RA patients show only minimal morphological changes, mainly in the glomerulus $(3,5,7,10,11,14,17)$. Other occasional findings are papillary necrosis, usually associated with non-steroidal anti-inflammatory drugs (NSAIDs) use, and nephrosclerosis which is frequent in autopsies of RA patients and is often the cause of renal failure $(4,24,25)$. Rheumatoid nodules in the kidney cortex are an exceptional histopathological finding (29).

Tubulointerstitial changes, both acute and chronic, are reported as the main lesions in less than $10 \%$ of biopsies, but they can be found in almost two thirds of RA patients $(9-11,14)$. Methotrexate precipitation in the renal tubules can cause acute kidney injury (2\%) (27). The clinical presentation of chronic alterations, such as interstitial fibrosis and tubular atrophy, is impairment of renal function with no urinary abnormalities. These alterations are common in elderly patients with long disease duration but in some cases they are related to NSAIDs use $(10,28,30)$.

Cyclosporine and

NSAIDs renal toxicity is not related to a specific histological pattern (31). Nevertheless, some severe renal alterations have been described with biological drugs, such as TNF- $\alpha$ inhibitors, tocilizumab and abatacept (24). TNF- $\alpha$ inhibitors might induce a variety of renal diseases, including GN, which is undistinguishable from lupus-like syndrome and usually recovers when the treatment is discontinued (24).

\section{SYSTEMIC LUPUS ERYTHEMATOSUS}

Lupus nephritis (LN) is among the most severe manifestations of systemic lupus erythematosus (SLE), occurring in up to $50-80 \%$ of patients, and can lead to end organ damage if not properly treated (32). Clinical manifestations are heterogeneous and often do not mirror the underlying histological abnormalities.

\section{Histological lesions: glomeruli}

Immune complexes (IC) are visible by IF and electronic microscopy (EM) and they are usually formed locally, triggering renal lesions according to the site of deposition $(33,34)$. Indeed, IC precipitation in the mesangium leads to activation of scavenging mesangial cells and secretion of extracellular matrix and cellular proliferation (35). IC localizing in the subendothelial space may directly harm endothelial cells and access the vascular space where they can activate the complement pathway and trigger recruitment of inflammatory cells (36-38). Conversely, IC deposition in the subepithelium is associated with less inflammation and podocyte damage, which can lead to 
nephron loss and glomerulosclerosis due to the poor renewal capability of podocytes (33, 36, 39). Wire loops are defined as capillary wall thickening due to abundant subendothelial IC deposition (33). Hyaline thrombi are not real thrombi but IC gathering in the capillary lumen, usually associated with subendothelial IC (33).

Cellular proliferation indicates hyperplasia of glomerular cells, depending both on increase in native cell number and infiltrating inflammatory cells, seen by light microscopy (LM) (33). Hyperplasia is due to the pro-inflammatory activity of IC and can affect either the mesangial, endocapillary or extracapillary compartment. Mesangial proliferation does not involve glomerular capillaries, which remain patent and normocellular; conversely, endocapillary proliferation leads to obliteration of capillary lumen and is frequently associated with proliferative LN $(33,39)$. Extracapillary proliferation of resident and inflammatory cells takes place in the urinary space and may trigger formation of cellular crescents, which indicate persistent inflammation, and can themselves progress to fibrosis. Proliferative lesions are frequently associated with active glomerular lesions including fibrinoid necrosis and lesions of the glomerular basement membrane (GBM), which in severe cases may cause rupture of the capillary wall and haemorrhage in the Bowman space.

\section{Histological lesions: tubule and interstitium}

The tubule-interstitial compartment is extensively involved in LN: increased inflammation and especially fibrosis at this level correlate with reduced renal function (33, $39,40)$. Initial lesions include the interstitial edema followed by interstitial fibrosis and tubular atrophy which indicate chronic damage; IC (IgG) deposition along the tubular basement membrane may be seen by IF or EM and correlate with glomerular IC deposition.

Renal arteries and arterioles are often affected by non-complicated IC deposition. However, more severe lesions are possible and include necrotizing lupus vasculopathy caused by IC-mediated arteriolar obstruction as well as non-specific lesions such as glomerular vasculitis or thrombotic microangiopathy, or sclerotic lesions following uncontrolled hypertension (33).

\section{Classification and prognostic utility of histology}

Since 1974, several classification systems have been developed for LN, all converging on characterization of glomerular lesions; currently the chosen set is the ISN/ RPS 2003 classification (Table I) (33-42). Despite several investigations into the role of a specific histological feature on patient outcome in the long term, data remain conflicting (42-44). Proliferative classes are considered the heralds of a more hazardous disease but they usually respond to initial therapy, while membranous class $\mathrm{V}$ may underlie a peculiar pathogenesis with a smoldering yet not harmless phenotype $(45,46)$. Moreover, according to more recent observations, it looks as if the point is not only the histological class the patient belongs to, but rather what is the ratio of chronic over active lesions and how extensive renal damage is, thereby considering not only glomerular but also tubular and vascular lesions $(47,48)$. Cellular and fibrous crescents, fibrinoid necrosis and interstitial fibrosis/tubular atrophy are indeed emerging as harmful markers of $\mathrm{LN}$, which can lead to a worse prognosis including end-stage renal disease $(43,47,49)$. Hence, a search for specific histological hallmarks as well as assessment of clinical parameters, especially baseline serum creatinine and urinary sediment, should always be added to histological classification in order to have a comprehensive picture of the patient's likely outcome $(47,50)$.

So far, renal biopsy still represents the gold standard for LN investigation and histology is a sufficient clinical criterion to classify patients as having SLE (51). Validated recommendations indicate as threshold for renal biopsy a persistently increased proteinuria $>0.5 \mathrm{~g} /$ day especially in the presence of active urinary sediment (52). This notwithstanding, the value of renal biopsy was challenged in the past and it still is, 
Table I - Classes of lupus glomerulonephritis and histological features according to ISN/RPS 2003 classification.

\begin{tabular}{|c|c|c|c|}
\hline $\begin{array}{l}\text { Class I LN } \\
\text { (minimal GN) }\end{array}$ & \multicolumn{3}{|c|}{$\begin{array}{l}\text { Glomerular histology is normal at light microscopy, while some mesangial IC deposits are visible by IF or EM. } \\
\text { There are no deposits along capillary walls (41). }\end{array}$} \\
\hline $\begin{array}{l}\text { Class II LN } \\
\text { (mesangial GN) }\end{array}$ & \multicolumn{3}{|c|}{$\begin{array}{l}\text { Mesangial proliferation can be seen by light microscopy, while IC mesangial deposits are seen by IF. Minimal IC } \\
\text { deposits may also be found at a subendothelial level, although this is not a typical feature and has a controversial } \\
\text { prognostic value }(33,41) \text {. }\end{array}$} \\
\hline \multirow[t]{3}{*}{$\begin{array}{l}\text { Class III LN } \\
\text { (focal GN) }\end{array}$} & \multirow{3}{*}{$\begin{array}{l}\text { Glomerular lesions involve }<50 \% \text { of total glomeruli } \\
\text { (focal) and have a segmental distribution (i.e. they } \\
\text { affect }<50 \% \text { of glomerular tuft). Endocapillary } \\
\text { proliferation is frequent and focal subendothelial } \\
\text { deposits may give rise to wire loops. Other active } \\
\text { lesions are necrosis and limited extracapillary } \\
\text { proliferation, with or without mesangial } \\
\text { proliferation (41). }\end{array}$} & \multirow{2}{*}{\multicolumn{2}{|c|}{$\begin{array}{l}\text { Lesions occurring in class III and IV } \\
\text { are distinguished between } \\
\text { Active (A) or Chronic (C) }\end{array}$}} \\
\hline & & & \\
\hline & & \multirow{2}{*}{$\begin{array}{l}\text { Endocapillary hypercellularity with } \\
\text { reduction in capillary lumen }+/- \\
\text { leukocyte infiltrate }\end{array}$} & \multirow{2}{*}{ Glomerulosclerosis } \\
\hline \multirow[t]{8}{*}{$\begin{array}{l}\text { Class IV LN } \\
\text { (diffuse GN) }\end{array}$} & \multirow{8}{*}{$\begin{array}{l}\text { Glomerular lesions involve }>50 \% \text { of total glomeruli } \\
\text { (diffuse) and are often global (i.e., they affect more } \\
\text { than } 50 \% \text { of glomerular tuft). According to whether } \\
\text { lesions are segmental or global, class IV can be } \\
\text { divided into class IV-(S) and IV-(G), the clinical } \\
\text { relevance of which is currently debated (42). In } \\
\text { class IV, subendothelial deposits are widespread } \\
\text { and more abundant than in class III, with a variable } \\
\text { mesangial proliferation (41). } \\
\text { Cellular crescents reflect a severe, long-lasting } \\
\text { disease and are more commonly found in class IV. } \\
\text { Cellular crescents may then progress to a fibrous } \\
\text { grade (fibrous crescents) forming true synechiae in } \\
\text { glomerulosclerosis (33). }\end{array}$} & & \\
\hline & & Karyorrhexis & \multirow{3}{*}{ Adhesions } \\
\hline & & Fibrinoid necrosis & \\
\hline & & GBM rupture & \\
\hline & & \multirow{2}{*}{$\begin{array}{l}\text { Cellular or fibrocellular crescents } \\
\text { Subendothelial deposits visible by } \\
\text { light microscopy (wire loops) }\end{array}$} & \multirow{4}{*}{ Fibrous crescents } \\
\hline & & & \\
\hline & & \multirow[t]{2}{*}{$\begin{array}{l}\text { Endoluminal IC aggregates } \\
\text { (hyaline thrombi) }\end{array}$} & \\
\hline & & & \\
\hline $\begin{array}{l}\text { Class V LN } \\
\text { (membranous GN) }\end{array}$ & \multicolumn{3}{|c|}{$\begin{array}{l}\text { This class is characterized by widespread subepithelial IC deposition, which triggers diffuse alterations of the GBM, } \\
\text { consisting of a wide uniform thickening of capillary walls leading to the formation of a neomembrane. } \\
\text { Mesangial proliferation is variable. Class V may be associated with class III or IV if subendothelial deposits } \\
\text { and/or endocapillary proliferation are present at a high rate }(39,41) \text {. }\end{array}$} \\
\hline $\begin{array}{l}\text { Class VI LN } \\
\text { (sclerohyaline GN) }\end{array}$ & \multicolumn{3}{|c|}{$\begin{array}{l}\text { Glomerulosclerosis involves }>90 \% \text { of all glomeruli and is accompanied by marked interstitial fibrosis, } \\
\text { tubular atrophy and chronic vascular damage. No active lesions are present (41). }\end{array}$} \\
\hline
\end{tabular}

GN, glomerulonephritis; LN, lupus nephritis; IF, immunofluorescence; EM, electronic microscopy; GBM, glomerular basement membrane; IC, immune complexes.

especially when facing an acute clinical picture with active urinary sediment, sustained proteinuria, hypertension and/or swelling or clinical signs of renal insufficiency, where renal biopsy is endowed with procedural risks $(53,54)$. Conversely, when alterations are less prominent but persist despite treatment it is mandatory to know how active renal lesions are and thus how aggressive the therapy should be, so histological examination is frequently not yet dispensable.

\section{SJÖGREN SYNDROME}

Primary Sjögren syndrome (pSS) can involve the kidney with a prevalence ranging from $18.4 \%$ to $67 \%$ (55). Nevertheless, re- nal involvement is frequently misdiagnosed due to different factors, such as the various classification criteria used by authors or the fact that tubular dysfunction, which is the most common alteration in pSS patients, is quite difficult to be recognized. The spectrum of pSS renal manifestations varies from isolated electrolyte disturbances to tubular interstitial nephritis (TIN) and acute or chronic GN. Since prognosis is reported to be good and favourable in most cases, kidney biopsy is not always encouraged, but it is strongly suggested for GN secondary to cryoglobulinemia and for differential diagnosis with other disorders (i.e. IgG4related disease and sarcoidosis) (56).

TIN is the most common kidney presentation in pSS (56-58). Clinically, it often 
results in renal tubular acidosis with moderate, acute or more frequently chronic renal disease and/or tubular proteinuria (56, $58,59)$. Histology shows an inflammatory infiltrate of $\mathrm{B}$ and $\mathrm{T}$ cells in the tubularinterstitium. When $\mathrm{B}$ cells are predominant (10\% of cases), an anti-B cell therapy (i.e. Rituximab) can be suggested for $\mathrm{pSS}$ with renal involvement (56). However, literature findings are contrasting: in a recent study on 95 patients, Jasek et al. showed that plasma cells can be the predominant cellular lines (up to $25 \%$ ), since they are detected in $75 \%$ of subjects with TIN (60). By contrast, another study observed that TIN mostly includes $T$ cells, particularly T CD4+ (61). Apart from these findings, diagnosis is tricky, due to tubular loss of proteins, which is not usually assessed by urinary exams; moreover, TIN with tubular atrophy often leads to chronic renal disease, which is a very aspecific condition $(55,56,60)$. Thus, a kidney biopsy is not mandatory to confirm a suspected renal tubular acidosis; however, when TIN is suspected, it should be performed to better define treatment and outcome $(56,59)$.

Another manifestation of renal involvement, though rarer than TIN, is acute or chronic GN, which occurs with haematuria, proteinuria, or even nephrotic syndrome $(55,59)$. Its incidence varies from $5 \%$ to $13.9 \%$ and it may often be associated with other rheumatic diseases (i.e. SLE or combined cryoglobulinemia); indeed, the majority of subjects with GN and pSS display IgM-containing cryoglobulins, along with low C4 levels $(55,62)$. Furthermore, the presence of $\mathrm{C} 3$ and IgM deposits in biopsy specimens further supports the idea that cryoglobulinemia might play a pathogenetic role for the development of GN in pSS (63). GN encompasses different entities: cryoglobulinemic membrane-proliferative GN, focal segmental glomerulosclerosis, mesangial proliferative GN, membranous nephropathy and minimal change disease; a single case of amyloidosis has also been recently reported $(64,65)$.

Membranoproliferative GN (type 1), secondary to cryoglobulinemia, occurs in up to $30 \%$ of patients with pSS and is the most common GN in pSS $(56,60,63)$. Unlike TIN, it can be easily suspected and diagnosed: it occurs with hypertension, proteinuria, haematuria, nephritic syndrome and rapidly progressive GN leading to acute renal failure (56). However, renal biopsy is essential to confirm cryoglobulinemia and for differential diagnosis with other glomerular lesions such as proliferative/membranoproliferative GN without cryoglobulinemia, where endoluminal thrombi, vasculitis and IgM sub-deposit are absent (66).

\section{SYSTEMIC SCLEROSIS}

Renal involvement is a rare but severe manifestation in patients affected with systemic sclerosis ( $\mathrm{SSc}$ ): it is more frequent in the cutaneous diffuse (4\%) than in the cutaneous limited form (2\%) of the disease (67).

The scleroderma renal crisis (SRC) is the principal renal manifestation observed in SSc, affecting $2-15 \%$ of patients in different cohorts (68-70). It is a life-threatening complication of SSc and has a 1-year mortality rate of $20-35 \%(71,72)$. The frequency of SRC appears to be decreasing: in a recent analysis on 637 patients with diffuse cutaneous SSc with a disease duration $<4$ years from the European League Against Rheumatism Scleroderma Trials and Research (EUSTAR) cohort, it has been shown that the prevalence of SRC was only $2.4 \%(73,74)$. SRC is defined by a severe or worsening arterial hypertension $(>150 / 85 \mathrm{mmHg}$ ) and a rapidly progressive, acute deterioration of renal function, evolving in kidney failure (75, 76). Concomitant abnormalities supporting the diagnosis of SRC include oligoanuria, non-nephrotic proteinuria, haematuria, mechanic haemolytic anaemia, moderate thrombocytopenia, renal sodium overload or pulmonary edema (77).

The cause of SRC is still unknown: the characteristic vascular injury and fibrosis of SSc might represent the risk factors for SRC. The decreased renal perfusion due to vasculopathy is thought to contribute to SRC, but the exact trigger factors of SRC remain to be clarified. The absence of inflammatory infiltrates in renal biopsy 
specimens and the presence of thickening/ cell proliferation in the arteriolar intima suggest that ischemia is the major cause of tissue damage (78). Nevertheless, autoimmunity with immune-system activation might be a trigger of endothelial activation: pathognomonic of SRC is the onion bulb aspect related to endothelial injury, mucinous vascular intimal thickening, proliferation of endothelial cells and vascular smooth muscle cells, and hyperplasia. Vascular remodelling leads to the obstruction of the vascular lumen that is promoted by the presence of glycoprotein/mucopolysaccharides and fibrinoid necrosis in the thickened intima as well as by the accumulation of glomerular intracapillary eosinophilic material corresponding to fibrin thrombi of arterial walls, without signs of inflammation (79). Platelet activation leads to the formation of thrombosis and thrombotic microangiopathy can be found in up to $43 \%$ of cases (80). The lesions are usually localized in small and medium arteries, especially in the interlobular arteries and arterioles and arcuate arteries, with adventitial fibrosis and intra-glomerular thrombosis (78). On renal biopsy specimens, vascular, glomerular, tubular and interstitial lesions can be seen, but the hallmark of SCR is a proliferative and obliterative arteriolar vasculopathy with hypertensive vascular damage, thrombotic vascular occlusion and onion skinning with intimal myoid ac-

Table II - The most common differential diagnosis of scleroderma renal crisis in systemic sclerosis (in order of frequency).

\begin{tabular}{|l|}
\hline ANCA-associated glomerulonephritis \\
\hline $\begin{array}{l}\text { Thrombotic thrombocytopenic purpura and } \\
\text { haemolytic uremic syndrome }\end{array}$ \\
\hline $\begin{array}{l}\text { Other vasculitides (i.e. polyarteritis nodosa, mixed } \\
\text { cryoglobulinemia and Goodpasture syndrome) }\end{array}$ \\
\hline Membranous nephropathies \\
\hline $\begin{array}{l}\text { Drug-induced nephropathies } \\
\text { (i.e. D-penicillamine or cyclosporin A) }\end{array}$ \\
\hline Oxalate nephropathy \\
\hline Renal artery stenosis \\
\hline Membranoproliferative nephropathies \\
\hline Pre-renal causes (i.e. sepsis, dehydration) \\
\hline
\end{tabular}

cumulation and adventitial fibrosis leading to glomerular ischemic collapse $(81,82)$.

Glomerular changes, usually focal, are often observed: Ig and complement deposits may be detected but are not specific (i.e. $\mathrm{IgM}, \operatorname{IgG}$ and $\operatorname{Ig} \mathrm{A}, \mathrm{C} 3$, or $\mathrm{C} 1 \mathrm{q}$ deposits in glomeruli or mesangium as well as in small arteries can be found). Notably, these changes can be observed also in renal biopsies from SSc patients without SRC and in cases of malignant hypertension in patients without SSc (83). Mesangiolysis may also be present. The ischemic process can affect also the tubular epithelium, with acute multifocal tubular necrosis and/or diffuse tubular atrophy (83).

Renal biopsy is not necessary to confirm the diagnosis of classic SRC but it plays a key role in cases with atypical presentation (i.e. normotensive patients) or in case of doubt with other causes of kidney damage (Table II) $(84,85)$. The mainstay of management of SCR is immediate initiation of angiotensin-converting enzyme (ACE)-inhibitors following a definite diagnosis (86).

\section{SYSTEMIC VASCULITIDES}

Vasculitides are an inflammatory process, histologically characterized by vessel wall destruction and vascular lumen occlusion leading to usually similar and overlapping clinical manifestations, so the final diagnosis sometimes may be uncertain. The kidneys could be affected directly by small vessel vasculitis (GN) or indirectly by medium to large vessel vasculitis (ischemic damage).

\section{ANCA-associated vasculitides}

Renal disease is a frequent and clinically unfavourable feature of ANCA-associated vasculitides (AAV), characterized by a wide spectrum of manifestations ranging from hypertension and sediment changes, to a rapidly progressive deterioration of renal function (87).

AAV are characterized by necrotizing vasculitis of small vessels and lack or paucity of immune deposits within the vessel wall (88). Granulomatosis with polyangiitis (GPA) differs from micro- 
scopic polyangiitis (MPA) due to the presence of a granulomatous inflammation, whereas eosinophilic GPA is usually associated with interstitial eosinophilic infiltrates $(89,90)$.

In all $\mathrm{AAV}$, the typical histopathological lesion is a pauci-immune crescentic focal and segmental necrotizing GN with negative IF staining, even if a weak granular staining pattern of $\operatorname{IgG}, \operatorname{IgM}$, or complement could be observed (91). LM shows focal thrombosis of glomerular capillaries with fibrinoid necrosis in early stages, and later on rupture of the GBM, karyorrhexis and poor definition of cellular membranes. In addition, the extracapillary proliferation, which consists in cell proliferation in the urinary space between the Bowman capsule and the capillary tuft, compresses the glomerular tuft and decreases the filtration surface, leading to a rapid loss of renal function (92). This results in crescent formation, initially predominantly cellular, leading later to more fibrous crescents. This $\mathrm{GN}$ is often associated with periglomerular accumulation of mononuclear cells while, periglomerular granulomatous reactions, synechiae and mesangial hypercellularity are less frequently observed (93).

The presence of a purely cellular extracapillary proliferation, interstitial edema, tubular necrosis and tubular intraepithelial infiltrates are associated with active disease. Conversely, long lasting kidney inflammation leads to glomerulosclerosis, interstitial fibrosis, arteriosclerosis and tubular atrophy (92). Notably, these irreversible scars together with tubular cast formation are more often reported in MPA as well as in renal limited vasculitis (AAV without extrarenal symptoms) compared to GPA. None of the above-mentioned lesions is specific for vasculitis; thus, renal histopathology, even if it is not useful for differential diagnosis, remains crucial for AAV prognosis (94).

\section{Other vasculitides associated with renal damage}

The pathognomonic elements for Goodpasture Syndrome are a typical linear staining for IgG in GBM on IF study and anti-GBM positivity at blood serology (95). However, this GN is indistinguishable from AAV pauci-immune crescentic GN at the LM because both, typically, have prominent fibrinoid necrosis and crescent formation without significant endocapillary proliferation. Moreover, there is a group of small vessel vasculitides that, as opposed to AAV, is characterized by IC deposits detectable by IF: cryoglobulinemic vasculitis, HenochSchoenlein purpura (HSP) and hypocomplementemic urticarial vasculitis (96).

Cryoglobulinemic GN is characterized by cryoglobulin deposits, which could lead to a membranoproliferative injury (97). Renal biopsy usually shows diffuse and global endocapillary cellular infiltrate rich in monocyte, even if neutrophils could be frequently seen in the acute phase. The typical lesion is a mesangial proliferation with eosinophilic and strongly periodic acid-Schiff (PAS) positive intra-luminal cryo-plugs while the GBM acquires double contours. One third of the patients have signs of leukocytoclastic vasculitis in renal small arteries, while crescents are rarely observed (97). IF reveals irregular subendothelial, mesangial and intra capillary deposits of IgM, IgG and complement (97). EM easily identifies the cryoglobulin deposits that usually present short fibrillary substructure and a tactoid organization, even if monoclonal cryoglobulins tend to acquire a more regular and more organized substructure (97-100).

HSP is a systemic vasculitis, typical of childhood, associated with IgA deposits. HSP nephritis and IgA nephropathy are considered related diseases with similar histological features and their differential diagnosis is mainly clinical because their histological findings are similar (101, 102). In both cases, on IF study, renal biopsy shows diffuse, granular and mesangial IgA deposits (more frequently formed by subclass $\operatorname{Ig} \mathrm{A} 1$ ), that are usually detectable also in the late and more fibrotic stages. The association of IgG and C3 deposition is also frequent while $\operatorname{IgM}$ deposits are more rarely reported. EM also detects the $\operatorname{IgA}$ deposits typically in the mesangium and capillary wall (sub endothe- 
lium) (101, 102). By LM, HSP nephritis is characterized by a broad spectrum of glomerular lesions depending on the timing of renal biopsy. In fact, it shows cellular infiltrate of mesangium and capillary lumen with fibrinoid sclerosis and small cellular crescent in early stages, leading to fibrous crescents in the late stages (101). However, the most important diagnostic and prognostic histological features are the presence and the extension of crescents that represent the prominent criteria of the International Study for Kidney Diseases in Children (ISKDC) histological classification for HSP nephropathy (Table III) (102). Crescents associated with endocapillary proliferation and glomerular sclerosis, currently head the most widely applied adult-HSP nephropathy classification (Table IV) (101-103). Extra-glomerular lesions include tubulointerstitial lesions, which are often associated with renal impairment and vascular lesions (e.g. intimal-media thickening of small arteries, interlobular artery arteriosclerosis and, very rarely, necrotizing vasculitis of a small arterial vessel) (101).

\section{ANTIPHOSPHOLIPID SYNDROME}

Renal involvement in antiphospholipid syndrome (APS) has been reported in about 9-25\% of cases with different clinical manifestations depending on the size and type of vessels where the thrombosis occurs (104). One of the most common clinical features is hypertension ( $>90 \%)$, which can occur with or without renal artery stenosis (e.g. the typical smooth and potentially reversible narrowing in the mid-portion of the renal artery) $(27,105)$. At the renal biopsy, APS nephropathy is characterized by acute and/or chronic lesions due to the arterial lesions but, besides renal infarction and ischemic changes, several types of glomerular lesions have been reported (e.g. proliferative or pauci-immune $\mathrm{GN}$, minimal change disease, membranous nephropathy, glomerulosclerosis) $(104,106)$. Thus, APS histology can often resemble the haemolytic-uremic syndrome or thrombotic thrombocytopenic purpura.

The elective treatment is the anticoagulation; the addition of immunosuppression

Table III - Histological classification of Henoch-Schoenlein purpura nephritis according to the International Study for Kidney Diseases in Children (ISKDC).

\begin{tabular}{|c|l|}
\hline Class & Histological features \\
\hline I & Minimal histological alteration \\
\hline II & Pure mesangial proliferation \\
\hline III & Focal (IIla) or diffuse (IIIb) mesangial proliferation with $<50 \%$ crescentic glomeruli \\
\hline IV & Focal (IVa) or diffuse (IVb) mesangial proliferation with $50-75 \%$ crescentic glomeruli \\
\hline V & Membranoproliferative-like glomerulonephritis \\
\hline
\end{tabular}

Table IV - Classification of glomerular lesions in adult Henoch-Schoenlein purpura.

\begin{tabular}{|c|l|l|}
\hline Class & Histological definition & Histological features \\
\hline I & Mesangiopathic glomerulonephritis & $\begin{array}{l}\text { Normal or subnormal glomeruli with mesangial thickening } \\
\text { and hypercellularity }\end{array}$ \\
\hline II & $\begin{array}{l}\text { Segmental and focal proliferative } \\
\text { glomerulonephritis }\end{array}$ & Focal and segmental proliferative lesions \\
\hline III & $\begin{array}{l}\text { Diffuse endocapillary proliferative } \\
\text { glomerulonephritis }\end{array}$ & $\begin{array}{l}\text { Diffuse exclusively endocapillary proliferative lesions } \\
\text { that may be segmental (Illa) or global (IIlb) } \\
\text { Class III b can be associated with extracapillary focal proliferation }\end{array}$ \\
\hline IV & $\begin{array}{l}\text { Endo and extra capillary } \\
\text { proliferative glomerulonephritis }\end{array}$ & $\begin{array}{l}\text { Extracapillary diffuse proliferation with focal or diffuse crescents } \\
\text { and the presence of endocapillary diffuse proliferative lesions. }\end{array}$ \\
\hline V & Kidney fibrosis & Terminal glomerular fibrosis \\
\hline
\end{tabular}


and plasmapheresis can be useful in selected patients with acute kidney injury related to APS in order to reduce the risk of chronic damage (27). In fact, it has been demonstrated that APS nephropathy increases the risk of end-stage renal disease as well as transplant failure and pregnancy complications in general population and especially in lupus patients $(104,107,108)$. Notably, isolated microangiopathic thrombosis is reported in $10 \%$ of lupus patients with antiphospholipid antibodies; however, it is important to document the absence of glomerular or arterial immune deposits by IF/ EM since the mainstay of therapy differs from the immunosuppression to anticoagulation therapy, as for primary APS (109). In addition, it has been reported that lupus patients with APS nephropathy more easily develop arterial thromboses while those without APS nephropathy usually develop venous thromboses (109). Thus, the presence of renal small-artery vasculopathy at the renal biopsy can be useful also for initiating a specific prophylaxis for APS, which is a well-known independent predictor of damage in SLE (110).

\section{OTHER RHEUMATIC DISEASES}

Nephropathy in mixed connective tissue disorder is uncommon, despite having been reported in up to $50 \%$ of patients, especially in children, with predominant but not severe glomerulopathy or interstitial/vascular disease depending on the predominant autoimmune features (111).

Renal involvement in idiopathic inflammatory myopathies (polymyositis, dermatomyositis and inclusion body myositis) occurs in $20-25 \%$ of patients (27). In dermatomyositis, histological findings vary widely, including a peculiar pattern of acute vascular damage and IC GN (mainly mesangial-proliferative and membranous GN) (112). In particular, rhabdomyolysis or drug induced acute kidney injury (10$11 \%$ ) can lead to several complications in the short term (i.e. sudden cardiac event) as well as in the long term (e.g. chronic renal disease in more than $80 \%$ of cases) (113).

\section{CONCLUSIONS}

Clinical-pathologic correlations derived from the study of renal tissue can be useful for differential diagnosis, prognosis assessment and therapeutic decisions in patients affected with rheumatic diseases. Thus, renal biopsy should be considered an important tool in the management of nephropathies in such patients.

\section{REFERENCES}

1. Bird HA. The kidney in rheumatic diseases. Ann Rheum Dis. 1989; 48: 1029-30.

2. Anders HJ, Vielhauer V. Renal co-morbidity in patients with rheumatic diseases. Arthrit Res Ther. 2011; 13: 222.

3. Yoshinaga Y, Nishiya K, Yamamura M. Study of urinary findings and renal functions in patients with rheumatoid arthritis. Kidney Dialysis. 1989; 26: 477-82.

4. Koivuniemi R, Paimela L, Suomalainen R, Leirisalo-Repo M. Renal diseases in patients with rheumatoid arthritis. Scand J Rheumatol. 2016; 45: 432-3.

5. Helin HJ, Korpela MM, Mustonen JT, Pasternack AI. Renal biopsy findings and clinicopathological correlations in rheumatoid arthritis. Arthritis Rheum. 1995; 38: 242-7.

6. Nakano M, In H, Saito T, et al. Renal disorders in rheumatoid arthritis. Nippon Rinsho. 1992; 50: 576-80.

7. Nakano M, Ueno M, Nishi S, et al. Determination of $\operatorname{IgA}$ - and IgM-rheumatoid factors in patients with rheumatoid arthritis with and without nephropathy. Ann Rheum Dis. 1996; 55: 520-4.

8. Nakano M, Ueno M, Nishi S. Analysis of renal pathology and drug history in 158 Japanese patients with rheumatoid arthritis. Clin Nephrol. 1998; 50: 154-60.

9. Siamopoulos K, Wilkinson R, Leohapand T, Morley AR. Renal biopsy appearances in rheumatoid disease. Clin Nephrol. 1983; 20: 114-20.

10. Makino H, Yoshinaga Y, Yamasaki Y, et al. Renal involvement in rheumatoid arthritis: analysis of renal biopsy specimens from 100 patients. Mod Rheumatol. 2002; 12: 148-54.

11. Vinicki JP, Pellet SC, De Rosa G, et al. Analysis of 65 renal biopsies from patients with rheumatoid arthritis (1976-2015): change in treatment strategies decreased frequency and modified histopathological findings. J Clin Rheumatol. 2015; 21: 335-40.

12. Korpela M, Mustonen J, Helin H, Pasternack A. Immunological comparison of patients 
with rheumatoid arthritis with and without nephropathy. Ann Rheum Dis. 1990; 49: 214-8.

13. Leonard PA, Bienz SR, Clegg D, Ward JR. Hematuria in patients with rheumatoid arthritis receiving gold and D-Penicillamine. J Rheumatol. 1987; 14: 55-9.

14. Ichikawa K, Konta T, Sato H, et al. The clinical and pathological characteristics of nephropathies in connective tissue diseases in the Japan Renal Biopsy Registry. Clin Exp Nephrol. 2017; 2 [Epub ahead of print].

15. Yoshida A, Morozumi K, Suganuma T. Clinicopathological study of nephropathy in patients with rheumatoid arthritis. Ryumachi. 1991; 31: 14-21.

16. Icardi A, Araghi P, Ciabattoni M, et al. Kidney involvement in rheumatoid arthritis. Reumatismo. 2003; 55: 76-85.

17. Krel' OV, Varshavskii VA, Kanevskaia MZ, et al. Kidney involvement in patients with rheumatoid arthritis. Ter Arkh. 1990; 62: 104-13.

18. Orjavik O, Brodwall EK, Oystese B, et al. A renal biopsy study with light and immunofluorescent microscopy in rheumatoid arthritis. Acta Med Stand. 1981; 645: 9-14.

19. Koivuniemi R, Paimela L, Suomalainen R, Leirisalo-Repo M. Amyloidosis as a cause of death in patients with rheumatoid arthritis. Clin Exp Rheumatol. 2008; 26: 408-13.

20. Harper L, Cockwell P, Howie AJ, et al. Focal segmental necrotizing glomerulonephritis in rheumatoid arthritis. Q J Med. 1997; 90: 125-32.

21. Mustila A, Korpela M, Mustonen J, et al. Perinuclear antineutrophil cytoplasmic antibody in rheumatoid arthritis: a marker of severe disease with associated nephropathy. Arthritis Rheum. 1997; 40: 710-7.

22. Boers M, Croonen AM, Dijkmans BA, et al. Renal findings in rheumatoid arthritis: clinical aspects of 132 necropsies. Ann Rheum Dis. 1987; 46: 658-63.

23. Messiaen T, M'bappe P, Boffa JJ. MPO-ANCA necrotizing glomerulonephritis related to rheumatoid arthritis. Am J Kidney Dis. 1998; 32: E6.

24. Piga M, Chessa E, Ibba V, et al. Biologics-induced autoimmune renal disorders in chronic inflammatory rheumatic diseases: systematic literature review and analysis of a monocentric cohort. Autoimmun Rev. 2014; 13: 873-9.

25. Mokuda S, Onishi M, Takasugi K. D-penicillamine-induced glomerulonephritis with crescent formation: remission following drug discontinuation. Indian J Nephrol. 2013; 23: 226-8.

26. Kaneko K, Nanki T, Hosoya T, et al. Etanercept-induced necrotizing crescentic glomerulonephritis in two patients with rheumatoid arthritis. Mod Rheumatol. 2010; 20: 632-6.
27. Mittal T, Rathi M. Rheumatological diseases and kidneys: a nephrologist's perspective. Int J Rheum Dis. 2014; 17: 834-44.

28. Ramirez G, Lambert L, Bloomer HA. Renal pathology in patients with rheumatoid arthritis. Nephron. 1981; 29: 124-6.

29. Schned AR, Moran M, Selikowitz SM, Taylor TH. Multiple rheumatoid nodules of the renal cortex. Arch Intern Med. 1990; 150: 891-3.

30. Levin ML. Patterns of tubulo-interstitial damage associated with nonsteroidal anti-inflammatory drugs. Semin Nephrol. 1988; 3: 55-61.

31. Schiff MH, Whelton A. Renal toxicity associated with disease-modifying antirheumatic drugs used for the treatment of rheumatoid arthritis. Semin Arthritis Rheum. 2000; 30: 196-208.

32. Doria A, Iaccarino L, Ghirardello A, et al. Long-term prognosis and causes of death in systemic lupus erythematosus. Am J Med. 2006; 119: 700-6.

33. Tsokos G, Buyon JP, Koike T, Lahita G, editors. The pathology of lupus nephritis. In: Systemic lupus erythematosus, 5th ed. Elsevier; 2016. Pp 351-69.

34. Gatto M, Iaccarino L, Ghirardello A, et al. Clinical and pathologic considerations of the qualitative and quantitative aspects of lupus nephritogenic autoantibodies: a comprehensive review. J Autoimmun. 2016; 69: 1-11.

35. Rekvig OP, Putterman C, Casu C, et al. Autoantibodies in lupus: culprits or passive bystanders? Autoimmun Rev. 2012; 11: 596-603.

36. Davidson A. What is damaging the kidney in lupus nephritis. Nat Rev Rheumatol. 2016; 12: 143-53.

37. Pérez de Lema G, Maier H, Nieto E, et al. Chemokine expression precedes inflammatory cell infiltration and chemokine receptor and cytokine expression during the initiation of murine lupus nephritis. J Am Soc Nephrol. 2001; 12: 1369-82.

38. Segerer S, Schlondorff D. Role of chemokines for the localization of leukocyte subsets in the kidney. Semin Nephrol. 2007; 27: 260-74.

39. Giannakis K, Faraggiana T. Histopathology of lupus nephritis. Clin Rev Allerg Immunol. 2011; 40: 170-80.

40. Pagni F, Galimberti S, Galbiati E, et al. Tubulointerstitial lesions in lupus nephritis: International multicentre study in a large cohort of patients with repeat biopsy. Nephrol. (Carlton). 2016; $21: 35-45$.

41. Weening J, D’Agati V, Schwartz MM, et al. The classification of glomerulonephritis in systemic lupus erythematosus revisited. J Am Soc Nephrol. 2004; 15: 241-50.

42. Vandepapelière J, Aydin S, Cosyns JP, et al. Prognosis of proliferative lupus nephritis subsets in the Louvain lupus nephritis inception cohort. Lupus. 2014; 23: 159-65. 
43. Rijnink EC, Tang YKO, Wilhelmus S, et al. Clinical and histopathologic characteristics associated with renal outcomes in lupus nephritis. Clin J Am Soc Nephrol. 2017; 12: 734-43.

44. Shariati-Sarabi Z, Ranjbar A, Monzavi SM, et al. Analysis of clinicopathologic correlations in Iranian patients with lupus nephritis. Int J Rheum Dis. 2013; 16: 731-8.

45. Norby GE, Mjøen G, Bjørneklett R, et al. Outcome in biopsy-proven Lupus nephritis: Evaluation of biopsies from the Norwegian Kidney Biopsy Registry. Lupus 2017; 1: 961203316686700 [Epub ahead of print].

46. Reich HN, Gladman DD, Urowitz MB, et al. Persistent proteinuria and dyslipidemia increase the risk of progressive chronic kidney disease in lupus erythematosus. Kidney Int. 2011; 79: 914-20.

47. Chen S, Chen H, Liu Z, et al. Pathological spectrums and renal prognosis of severe lupus patients with rapidly progressive glomerulonephritis. Rheumatol Int. 2015; 35: 709-17.

48. Hu WX, Liu ZZ, Chen HP, et al. Clinical characteristics and prognosis of diffuse proliferative lupus nephritis with thrombotic microangiopathy. Lupus. 2010; 19: 1591-8.

49. Chen S, Tang Z, Zhang H, et al. Prediction of renal outcomes in patients with crescentic lupus nephritis. Am J Med Sci. 2015; 349: 298305.

50. Martínez-Martínez MU, Llamazares-Azuara LM, Martínez-Galla D, et al. Urinary sediment suggests lupus nephritis histology. Lupus 2017; 26: 580-7.

51. Petri M, Orbai AM, Alarcón GS, et al. Derivation and validation of the Systemic Lupus International Collaborating Clinics classification criteria for systemic lupus erythematosus. Arthritis Rheum. 2012; 64: 2677-86.

52. Bertsias GK, Tektonidou M, Amoura Z, et al. Joint European League Against Rheumatism and European Renal Association-European Dialysis and Transplant Association (EULAR/ ERA-EDTA) recommendations for the management of adult and paediatric lupus nephritis. Ann Rheum Dis. 2012; 71: 1771-82.

53. Giannico G, Fogo A. Lupus nephritis: is the kidney biopsy currently necessary in the management of lupus nephritis? Clin J Am Soc Nephrol. 2013; 8: 138-54.

54. Arriens C, Chen S, Karp DR, et al. Prognostic significance of repeat biopsy in lupus nephritis: Histopathologic worsening and a short time between biopsies is associated with significantly increased risk for end stage renal disease and death. Clin Immunol. 2016; 3 pii: S1521-6616(16)30668-4 [Epub ahead of print].

55. Ren H, Wang WM, Chen XN, et al. Renal involvement and follow-up of 130 patients with primary Sjögren's syndrome. J Rheumatol. 2008; 35: 278-84.

56. François H, Mariette X. Renal involvement in primary Sjögren syndrome. Nat Rev Nephrol. 2016; 12: 82-93.

57. Kidder D, Rutherford E, Kipgen D, et al. Kidney biopsy findings in primary Sjögren syndrome. Nephrol Dial Transplant. 2015: 30: 1363-9.

58. Maripuri S, Grande JP, Osborn TG, et al. Renal involvement in primary Sjögren syndrome: a clinicopathologic study. Clin J Am Soc Nephrol. 2009; 4: 1423-31.

59. Ramos-Casals M, Brito-Zeròn P, Seror R, et al. Characterization of systemic disease in primary Sjögren's syndrome: EULAR-SS Task Force recommendations for articular, cutaneous, pulmonary and renal involvements. Rheumatology. 2015; 54: 2230-38.

60. Jasiek M, Karras A, Le Guern V, et al. A multicentre study of 95 biopsy-proven cases of renal disease in primary Sjögren's syndrome. Rheumatology. 2017; 56: 362-70.

61. Evans RDR, Laing CM, Ciurtin C, Walsh SB. Tubulointerstitial nephritis in primary Sjögren syndrome: clinical manifestations and response to treatment. BMC Musculoskel Disord. 2016; 17: 2.

62. Bossini N, Savoldi S, Franceschini F, Mombelloni S, Baronio M, Cavazzana I, et al. Clinical and morphological features of kidney involvement in primary Sjögren's syndrome. Nephrol Dial Transplant. 2001; 16: 2328-36.

63. Goules AV, Tatouli IP, Moutsopoulos HM, et al. Clinically significant renal involvement in primary Sjögren's syndrome. Clinical presentation and outcome. Arthrit Rheum. 2013; 65: 2945-53.

64. Kronbichler A, Mayer G. Renal involvement in autoimmune connective tissue diseases. BMC Med. 2013; 11: 95.

65. Ooms V, Decupere M, Lerut E, et al. Secondary renal amyloidosis due to long-standing tubulointerstitial nephritis in a patient with Sjögren syndrome. Am J Kidney Dis. 2005: 46: e75-80.

66. Anand A, Krishna GG, Sibley RK, Kambham N. Sjögren syndrome and cryoglobulinemic glomeurlonephritis. Am J Kidney Dis. 2015; 66: 532-35.

67. Minier T, Guiducci S, Bellando-Randone S, et al. Preliminary analysis of the very early diagnosis of systemic sclerosis (VEDOSS) EUSTAR multicentre study: evidence for puffy fingers as a pivotal sign for suspicion of systemic sclerosis. Ann Rheum Dis. 2014; 73: 2087-93.

68 Penn H, Howie AJ, Kingdon EJ, et al. Scleroderma renal crisis: patient characteristics and long-term outcomes. QJM 2007; 100: 485-94. 
69. Teixeira L, Mouthon L, Mahr A, et al. Mortality and risk factors of scleroderma renal crisis: a French retrospective study of 50 patients. Ann Rheum Dis. 2008; 67: 110-6.

70. Muangchan C; Canadian Scleroderma Research Group, Baron M, Pope J. The $15 \%$ rule in scleroderma: the frequency of severe organ complications in systemic sclerosis. A systematic review. J Rheumatol. 2013; 40: 1545-56.

71. Cozzi F, Marson P, Cardarelli S, et al. Prognosis of scleroderma renal crisis: a long term observational study. Nephrol Dial Transplant. 2012; 27: 4398-403.

72. Guillevin L, Berezne A, Seror R, et al. Scleroderma renal crisis: a retrospective multicenter study on91 patients and 427 controls. Rheumatology. 2012; 51: 460-7.

73. Turk M, Pope JE. The frequency of scleroderma renal crisis over time: a metaanalysis. J Rheumatol. 2016; 43: 1350-55.

74. Maurer B, Graf N, Michel BA, et al. Prediction of worsening of skin fibrosis in patients with diffuse cutaneous systemic sclerosis using the EUSTAR database. Ann Rheum Dis. 2015; 74: 1124-31.

75. Steen VD. Scleroderma renal crisis. Rheum Dis Clin North Am. 2003; 29: 315-33.

76. Mouthon L, Bussone G, Berezné A, et al. Scleroderma renal crisis. J Rheumatol. 2014; 41: 1040-8.

77. Lynch BM, Stern EP, Ong V, et al. UK Scleroderma Study Group (UKSSG) guidelines on the diagnosis and management of scleroderma renal crisis. Clin Exp Rheumatol. 2016; 34: 106-9.

78. Mouthon L, Bérezné A, Bussone G, et al. Scleroderma renal crisis: a rare but severe complication of systemic sclerosis. Clin Rev Allergy Immunol. 2011; 40: 84-91.

79. Woodworth TG, Suliman YA, Furst DE, Clements P. Scleroderma renal crisis and renal involvement in systemic sclerosis. Nat Rev Nephrol. 2016; 12: 678-91.

80. Steen VD. Scleroderma renal crisis. Rheum Dis Clin North Am. 2003; 29: 315-33.

81. Batal I, Domsic RT, Shafer A, et al. Renal biopsy findings predicting outcome in scleroderma renal crisis. Hum Pathol. 2009; 40: 332-40.

82. Ghossein C, Varga J, Fenves AZ. Recent developments in the classification, evaluation, pathophysiology, and management of scleroderma renal crisis. Curr Rheumatol Rep. 2016; 18: 5.

83. Mayes MD. Systemic sclerosis. Rheum Dis Clin North Am. 2015; 4: 13.

84. Mouthon L, Bussone G, Berezné A, et al. Scleroderma renal crisis. J Rheumatol. 2014; 41: 1040-8.

85. Hoa S, Stern EP, Denton CP, et al. Towards developing criteria for scleroderma renal crisis: a scoping review. Autoimmun Rev. 2016; 4: 407-15.
86. Hudson M, Baron M, Tatibouet S, et al. Exposure to ACE inhibitors prior to the onset of scleroderma renal crisis-results from the International Scleroderma Renal Crisis Survey. Semin Arthritis Rheum. 2014; 43: 666-72.

87. Mahr A, Girard T, Agher R, Guillevin L. Analysis of factors predictive of survival based on 49 patients with systemic Wegener's granulomatosis and prospective follow-up. Rheumatology (Oxford). 2001; 40: 492-8.

88. Franssen CFM, Stegeman CA, Kallenberg CGM, et al. Antiproteinase 3- and antimyeloperoxidase-associated vasculitis. Kidney Int. 2000; 57: 2195-206.

89. Hagen EC, Daha MR, Hermans J, et al. Diagnostic value of standardized assays for anti-neutrophil cytoplasmic antibodies in idiopathic systemic vasculitis. EC/BCR Project for ANCA Assay Standardization. Kidney Int. 1998; 53: 743-53.

90. Kikuchi Y, Ikehata N, Tajima O, et al. Glomerular lesions in patients with ChurgStrauss syndrome and the anti-myeloperoxidase antibody. Clin Nephrol. 2001; 55: 429-35.

91. Jennette JC, Wilkman AS, Falk RJ. Antineutrophil cytoplasmic autoantibody associated glomerulonephritis and vasculitis. Am J Pathol. 1989; 135: 921-30.

92. Hauer HA, Hagen EC, de Heer E, et al. Glomerulonephritis in the vasculitides: advances in immunopathology. Curr Opin Rheumatol. 2003; 15: 17-21.

93. Kallenberg CG. The diagnosis and classification of microscopic polyangiitis. J Autoimmun. 2014; 48-49: 90-3.

94. Hauer HA, Bajema IM, van Houwelingen $\mathrm{HC}$, et al. Renal histology in ANCA-associated vasculitis: differences between diagnostic and serologic subgroups. Kidney Int. 2002; 61: 80-9.

95. Kaldas A, Warraich I, Prabhakar SS. ANCA associated glomerulonephritis- an in-depth review. J Nephrol Ther. 2013; 4: 147.

96. Jennette JC, Falk RJ, Bacon PA, et al. 2012 revised International Chapel Hill Consensus Conference nomenclature of vasculitides. Arthritis Rheum. 2013; 65: 1-11.

97. Fogo A, Kashgarian M. Diagnostic Atlas of renal pathology. 3rd ed. Elsevier. 2016.

98. Brouet JC, Clauvel JP, Danon F, et al. Biologic and clinical significance of cryoglobulins. A report of 86 cases. Am J Med. 1974; 57: 775-88.

99. Terrier B, Cacoub P. Renal Involvement in HCV-related vasculitis. Clin Res Hepatol Gastroenterol. 2013; 37: 334-9.

100. Beddhu S, Bastacky S, Johnson JP. The clinical and morphologic spectrum of renal cryoglobulinemia. Medicine (Baltimore). 2002; 81: 398-409. 
101. Pillebout E, Verine J. Henoch-Schönlein purpura in the adult. Rev Med Intern. 2014; 35: 372-81.

102. Davin JC, Coppo R. Henoch-Schönlein purpura nephritis in children. Nat Rev Nephrol. 2014; 10: 563-73.

103. Pillebout E, Thervet E, Hill G, et al. HenochSchönlein purpura in adults: outcome and prognostic factors. J Am Soc Nephrol. 2002; 13: 1271-8.

104. Sciascia S, Cuadrado MJ, Khamashta M, Roccatello D. Renal involvement in antiphospholipid syndrome. Nat Rev Nephrol. 2014;10: 279-89.

105. Sangle S, D'Cruz D, Jan W, et al. Renal artery stenosis in the antiphospholipid (Hughes) syndrome and hypertension. Ann Rheum Dis. 2003; 62: 999-1002.

106. Sinico RA, Cavazzana I, Nuzzo M, et al. Renal involvement in primary antiphospholipid syndrome: retrospective analysis of 160 patients. Clin J Am Soc Nephrol. 2010; 5: 1211.

107. Moroni G, Ventura D, Riva P, et al. Antiphospholipid antibodies are associated with an increased risk for chronic renal insufficiency in patients with lupus nephritis. Am J Kidney Dis. 2004; 43: 28.

108. Ducloux D, Pellet E, Fournier V, et al. Preva- lence and clinical significance of antiphospholipid antibodies in renal transplant recipients. Transplantation. 1999; 67: 90.

109. Tektonidou MG, Sotsiou F, Nakopoulou L, et al. Antiphospholipid syndrome nephropathy in patients with systemic lupus erythematosus and antiphospholipid antibodies: prevalence, clinical associations, and longterm outcome. Arthritis Rheum. 2004; 50: 2569.

110. Zen M, Iaccarino L, Gatto M, et al. Prolonged remission in Caucasian patients with SLE: prevalence and outcomes. Ann Rheum Dis. 2015; 74: 2117-22.

111. Kitridou RC, Akmal M, Turkel SB, et al. Renal involvement in mixed connective tissue disease: a longitudinal clinicopathologic study. Semin Arthritis Rheum. 1986; 16: 135-45.

112. Couvrat-Desvergnes G, Masseau A, Benveniste $\mathrm{O}$, et al. The spectrum of renal involvement in patients with inflammatory myopathies. Medicine (Baltimore). 2014; 93: 33-41.

113. Yen TH, Lai PC, Chen CC, et al. Renal involvement in patients with polymyositis and dermatomyositis. Int J Clin Pract. 2005; 59: 188-93. 